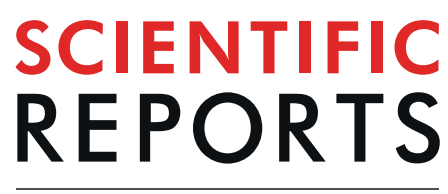

\title{
Ambulance Services Associated with Extreme Temperatures and Fine Particles in a Subtropical Island
}

\author{
Yu-Chun Wang ${ }^{1,7}$, Yu-Kai Lin ${ }^{2,7}$, Yi-Jhih Chen ${ }^{1}$, Shih-Chan Hung ${ }^{3}$, Yasmin Zafirah ${ }^{1} \&$ \\ Fung-Chang Sung ${ }^{4,5,6 *}$
}

This study evaluated the association between the risk of events requiring ambulance services and the ambient temperature and particulate matter of $2.5 \mu \mathrm{m}\left(\mathrm{PM}_{2.5}\right)$ and $10 \mu \mathrm{m}\left(\mathrm{PM}_{10}\right)$ for populations living in subtropical Taiwan. We used a distributed lag nonlinear model with a quasi-Poisson function to assess the roles of ambient temperature, $\mathrm{PM}_{10}$ and $\mathrm{PM}_{2.5}$ in the use of ambulance services for respiratory distress, coma and unconsciousness, chest pain, lying down in public, headaches/dizziness/vertigo/ fainting/syncope and out-of-hospital cardiac arrest (OHCA). The relative risk (RR) and 95\% confidence interval (Cl) of each specific event were calculated in association with the ambient conditions. In general, the events that required ambulance services had a V-shaped or J-shaped association with the temperature, where the risks were higher at extreme temperatures. The RR of each event was significant when the patients were exposed to temperatures in the $5^{\text {th }}$ percentile $\left(<15^{\circ} \mathrm{C}\right)$; patients with OHCA had the highest adjusted RR of $1.61(95 \% \mathrm{Cl}=1.47-1.77)$. The risks were also significant for coma/ unconsciousness, headaches/dizziness/vertigo/fainting/syncope, and OHCA but not for respiratory distress, chest pain and lying down in public, after exposure to the $99^{\text {th }}$ percentile temperatures of $>30^{\circ} \mathrm{C}$. The risks for use of ambulance services increased with PM exposure and were significant for events of respiratory distress, chest pain and OHCA after exposure to the $99^{\text {th }}$ percentile $\mathrm{PM}_{2.5}$ after controlling for temperatures. Events requiring ambulance services were more likely to occur when the ambient temperature was low than when it was high for the population on the subtropical island of Taiwan. The association of the risk of events requiring ambulance services with PM were not as strong as the association with low temperatures.

The increased frequency and intensity of extreme climate events are important public health concerns ${ }^{1}$. Studies have reported that ambient temperature and air pollution are important factors with significant impacts associated with various morbidities and mortalities $^{2-4}$. The associations between mortality and the temperature have been characterized by U-shaped, V-shaped and J-shaped curves ${ }^{5,6}$, with mortality increasing at extremely cold and/or extremely hot temperatures ${ }^{7,8}$. Studies have also found that the risk of emergency room visits for out-of-hospital cardiac arrest (OHCA) was greater in cold seasons than in hot seasons ${ }^{9-11}$. In Taiwan, the cumulative 6-day relative risk of emergency room visits for OHCA reaches 1.73 when the mean temperature is $14^{\circ} \mathrm{C}$ in comparison to when it is $>27^{\circ} \mathrm{C}$ after controlling for air pollution ${ }^{12}$.

Climate conditions have important impacts on the transport and dispersion of air pollutants. The role of pollutants in health impacts may thus vary with climate conditions ${ }^{13}$. However, studies may emphasize the impacts of air pollution rather than temperature on health, especially for respiratory diseases. One study that used the Danish Diet, Cancer, and Health cohort to follow 53,695 adults aged 50-65 years for a median of 10.2 years $^{14}$ found that $\mathrm{NO}_{2}$ exposure increased the risk of hospitalization for asthma and chronic obstructive pulmonary

\footnotetext{
${ }^{1}$ Department of Environmental Engineering, College of Engineering, Chung Yuan Christian University, 200 Chung-Pei Road, Zhongli, 320, Taiwan. ${ }^{2}$ Department of Health and Welfare, University of Taipei College of City Management, 101 Zhongcheng Road Sec. 2, Taipei, 111, Taiwan. ${ }^{3}$ Department of Emergency Services, Ministry of Health and Welfare Nantou Hospital, Nantou, 540, Taiwan. ${ }^{4}$ Department of Health Services Administration, China Medical University, 91 Hsueh-Shih Road, Taichung, 404, Taiwan. ${ }^{5}$ Management Office for Health Data, China Medical University Hospital, Taichung, 404, Taiwan. ${ }^{6}$ Department of Food Nutrition and Health Biotechnology, Asia University, Taichung, 413, Taiwan. ${ }^{7}$ These authors contributed equally:Yu-Chun Wang and Yu-Kai Lin. *email: fcsung1008@yahoo.com
} 
disease but not for stroke. No climate factors were considered in the Danish study. Cheng et al. ${ }^{15}$ also found that the air pollution in Kaohsiung, Taiwan, increased the risk of hospital admission for pneumonia in people with upper respiratory infections. The impact was found to be greater on cold days than on warm days, indicating that the climate played a role. Pneumonia is a significant consequence of influenza and cold symptoms, which appear mainly in the cold season.

Studies found that the ambulance dispatch services in Italy and Japan increased due to emergency events of OHCA, respiratory disorders and chest pain, etc., during a period with extreme temperatures ${ }^{16,17}$. A recent study found a 2 -fold increase in the use of emergency ambulance services in Taiwan within a 10-year period ${ }^{18}$. In contrast to visits for nonurgent conditions, which mostly occur at hospital emergency departments ${ }^{19}$, the number of ambulance emergency calls may be attributed to complicated conditions including delayed arrival times, restricted service times, and hard-to-reach locations. Moreover, a call is considered to be covered if it is responded to within a predefined standard time of 10 minutes in an urban area ${ }^{20}$. Most citizens use public ambulance systems as their initial entry points for receiving urgent care ${ }^{21}$. Ambulance call-out data provide new and valuable real-time information that is useful for assessing the impacts of environmental conditions, such as temperature and air pollution, on human health ${ }^{22}$.

Taiwan is a $150 \mathrm{~km}$ wide and $350 \mathrm{~km}$ long subtropical island within a relatively narrow range of longitude and latitude $\left(22-25^{\circ} \mathrm{N}, 120-122^{\circ} \mathrm{E}\right)$ and an annual average temperature of $24^{\circ} \mathrm{C}$, which varies from north to south ${ }^{23}$. The mean daily temperatures in urban areas range from $8^{\circ} \mathrm{C}$ in the winter to $33^{\circ} \mathrm{C}$ in the summer. The present study evaluated the relationship between the use of ambulance services and the ambient temperature conditions and fine particulate matter of $2.5 \mu \mathrm{m}$ and $10 \mu \mathrm{m}\left(\mathrm{PM}_{2.5}\right.$ and $\left.\mathrm{PM}_{10}\right)$.

\section{Materials and Methods}

Data Sources. We obtained the ambulance services data from the Ministry of Health and Welfare, meteorological data from the Central Weather Bureau (CWB) and hourly air pollution monitoring records from the Environmental Protection Administration (EPA) of Taiwan, all from 2006 to 2014. The ambulance services database contained information on the gender and age of the patient, the reason for the ambulance care call, and the location and time the service was dispatched for the event. All personal identification had been scrambled into surrogate numbers for privacy protection before the data file was released to users. From the medical records in the ambulance services data, the patients diagnosed with respiratory distress, coma and unconsciousness, chest pain, headaches/dizziness/vertigo/fainting/syncope, lying down in public, and out-of-hospital cardiac arrest in 15 cities and counties in Taiwan were identified, with the exception of the Taipei metropolitan area, which is the most urbanized area in Taiwan. The daily cause-specific number of these events requiring ambulance services in the area were analyzed for associations with the ambient environmental conditions.

The CWB meteorological records consisted of hourly weather data, which included the average temperature $\left({ }^{\circ} \mathrm{C}\right)$, maximum temperature $\left({ }^{\circ} \mathrm{C}\right)$, minimum temperature $\left({ }^{\circ} \mathrm{C}\right)$, relative humidity $(\%)$, wind speed $(\mathrm{m} / \mathrm{s})$, and barometric pressure, that were monitored at 25 real-time surface meteorological observatories around Taiwan. For areas without observatory stations, such as Taoyuan, Miaoli, Changhua, Yunlin, and Nantou, the weather data were obtained from the nearest surface meteorological observatory (Fig. 1).

The Taiwan air quality monitoring network has been in operation since 1993 and provides hourly records of ambient air pollutants, such as $\mathrm{PM}_{10}$, sulfur dioxide, nitrogen dioxide $\left(\mathrm{NO}_{2}\right)$, ozone, and carbon monoxide measured at the 76 stationary monitoring stations distributed throughout the island (Fig. 1). $\mathrm{PM}_{2.5}$ has been monitored since 2006. Detailed information on the monitoring instruments, stations, and quality assurance criteria are available through the Taiwan EPA website (https://taqm.epa.gov.tw/taqm/en/default.aspx).

Statistical Models. Nonlinear association between the daily ambient environmental and health risks. The daily means and ranges of the ambient environmental characteristics and the numbers of patients receiving ambulance services by the cause of the event from 2006 to 2014 were calculated for all regions of Taiwan. This study adopted a distributed lag nonlinear model (DLNM) with a quasi-Poisson function, as proposed by Gasparrini et al. ${ }^{24}$, to assess the nonlinear exposure-response relationship and a delayed association between the daily ambient environment and the cause-specific number of events requiring ambulance services, which was specified as follows:

$$
\begin{aligned}
\log [\mathrm{Y}] & \sim \mathrm{BS}(\mathrm{T}, \text { lag }=3 \text { day })+\mathrm{BS}\left(\mathrm{PM}_{2.5} \text { or } \mathrm{PM}_{10}, \text { lag }=5 \text { day }\right) \\
& +\mathrm{NS}\left(\mathrm{NO}_{2}, 4\right)+\mathrm{NS}(\text { date, } 4 \text { per year })+\mathrm{NS}(\text { ws, } 4)+\mathrm{NS}(\mathrm{rh}, 4) \\
& + \text { holiday effect }+ \text { dow }+\mathrm{PI}
\end{aligned}
$$

where $Y$ is the cause-specific daily number of events requiring ambulance services in a specific area, and $T$ is the area-specific daily mean temperature. The reference temperature was set at $25^{\circ} \mathrm{C}$ for all categories. This temperature was selected because we observed that it was the temperature with the lowest frequency of ambulance calls. We used the basis spline $(B S)$ function with 4 degrees of freedom $(\mathrm{d} f$ ) for the daily average temperature to estimate the association between the temperature and the health risk, and the effects were estimated and accumulated for 4 days. Most studies accumulate the lag effects of the ambient temperature on morbidity from a lag of 0 to a lag of $3^{25}$. The area-specific daily $\mathrm{PM}_{10}$ and $\mathrm{PM}_{2.5}$ concentrations were included in the model and set with $4 d f$. The daily $\mathrm{NO}_{2}$ concentration, wind speed (ws) and relative humidity (rh) were included in the model and set in the natural spline (NS) function with $4 \mathrm{~d} f$. dow indicates the day of the week. The daily deaths from pneumonia and influenza (PI) were also included in the model. The model selection was based on the lower Akaike information criterion value.

The relative risk (RR) and the related 95\% confidence interval (CI) calculations for each cause of an emergency ambulance service event that was associated with extreme temperatures in the $5^{\text {th }}$ and $99^{\text {th }}$ percentiles relative to $25^{\circ} \mathrm{C}$ were controlled for the $\mathrm{PM}$ and $\mathrm{NO}_{2}$ concentrations, wind speed, relative humidity, holiday effect, day of a 


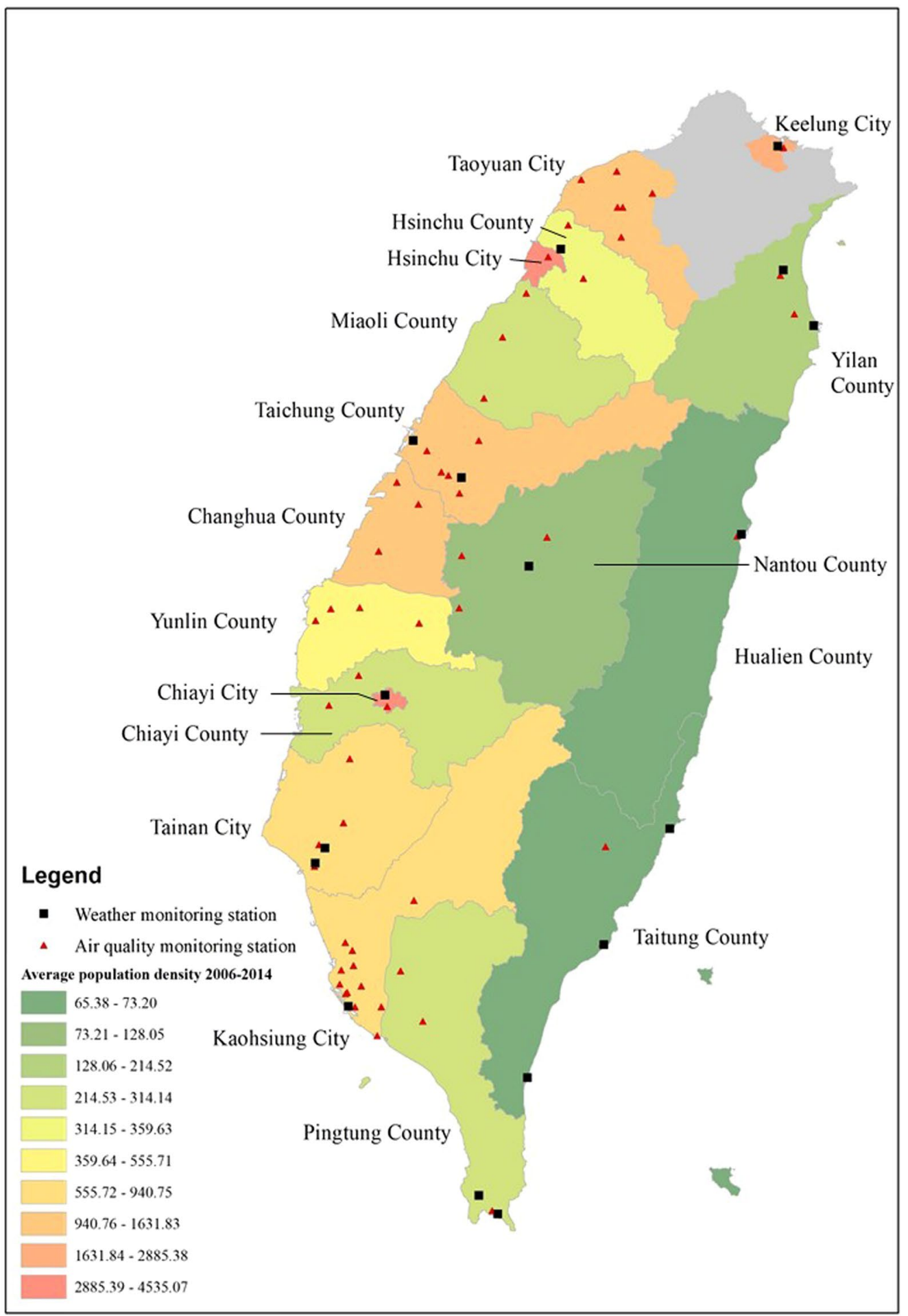

Figure 1. Locations of weather observatories and ambient air quality monitor stations.

week, mortality from pneumonia and influenza, and long-term time trend. We further calculated the relative risk of each cause by the increase of $\mathrm{PM}_{10}$ relative to $40 \mu \mathrm{g} / \mathrm{m}^{3} \mathrm{PM}_{10}(\mathrm{Q} 1)$ and by the increase of $\mathrm{PM}_{2.5}$ relative to $20 \mu \mathrm{g} /$ $\mathrm{m}^{3} \mathrm{PM}_{2.5}(\mathrm{Q} 1)$, without and with controlling for temperature.

Meta-analysis. We calculated the area-specific relative risk and the $95 \% \mathrm{CI}$ of the cause-specific ambulance events for each county and city in association with the temperature (Supplementary Figs. S1-S6) and the $\mathrm{PM}_{10}$ (Supplementary Figs. S7-S12) and $\mathrm{PM}_{2.5}$ concentrations (Supplementary Figs. S13-S18). We further integrated the relative risk of each ambulance services event for all areas into a relative risk of the ambulance services events for the whole Taiwan area through multivariate meta-analysis. The reference temperature was also set at 


\begin{tabular}{|c|c|c|c|c|c|c|c|}
\hline Parameters & Mean & S.D. & Minimum & Q1 & Q2 & Q3 & Maximum \\
\hline \multicolumn{8}{|l|}{ Ambulance Services } \\
\hline Respiratory distress & 63.0 & 18.7 & 22.0 & 48.0 & 62.0 & 76.0 & 149 \\
\hline Coma and unconsciousness & 53.4 & 16.8 & 16.0 & 40.0 & 53.0 & 65.0 & 125 \\
\hline Chest pain & 31.2 & 10.8 & 6.00 & 23.0 & 31.0 & 39.0 & 65.0 \\
\hline Headache/dizziness/vertigo/fainting/syncope & 79.6 & 20.4 & 33.0 & 64.0 & 78.0 & 94.0 & 168 \\
\hline Lying in public & 27.1 & 7.43 & 7.00 & 22.0 & 27.0 & 32.0 & 55.0 \\
\hline Out-of-hospital cardiac arrest & 30.5 & 12.1 & 0 & 22.0 & 30.0 & 38.0 & 76.0 \\
\hline \multicolumn{8}{|l|}{ Vital statics } \\
\hline Pneumonia and influenza & 17.9 & 5.94 & 2 & 14.0 & 17.0 & 22.0 & 44.0 \\
\hline \multicolumn{8}{|l|}{ Environmental factors } \\
\hline Temperature $\left({ }^{\circ} \mathrm{C}\right)$ & 23.4 & 4.60 & 10.6 & 19.6 & 24.2 & 27.5 & 31.0 \\
\hline Relative humidity (\%) & 76.7 & 5.71 & 53.9 & 73.5 & 77.1 & 80.5 & 93.0 \\
\hline Wind speed $(\mathrm{m} / \mathrm{s})$ & 2.56 & 0.88 & 1.14 & 1.93 & 2.31 & 2.97 & 9.84 \\
\hline $\mathrm{PM}_{10}\left(\mu \mathrm{g} / \mathrm{m}^{3}\right)$ & 54.0 & 22.7 & 17.4 & 37.1 & 49.9 & 66.7 & 372 \\
\hline $\mathrm{PM}_{2.5}\left(\mu \mathrm{g} / \mathrm{m}^{3}\right)$ & 30.2 & 13.3 & 6.65 & 19.9 & 27.9 & 38.2 & 106 \\
\hline $\mathrm{NO}_{2}(\mathrm{ppb})$ & 14.6 & 4.23 & 3.32 & 11.0 & 14.2 & 17.4 & 35.8 \\
\hline
\end{tabular}

Table 1. Characteristics of daily ambient environment conditions and daily cause-specific cases cared by ambulance services in Taiwan from 2006 to 2014.

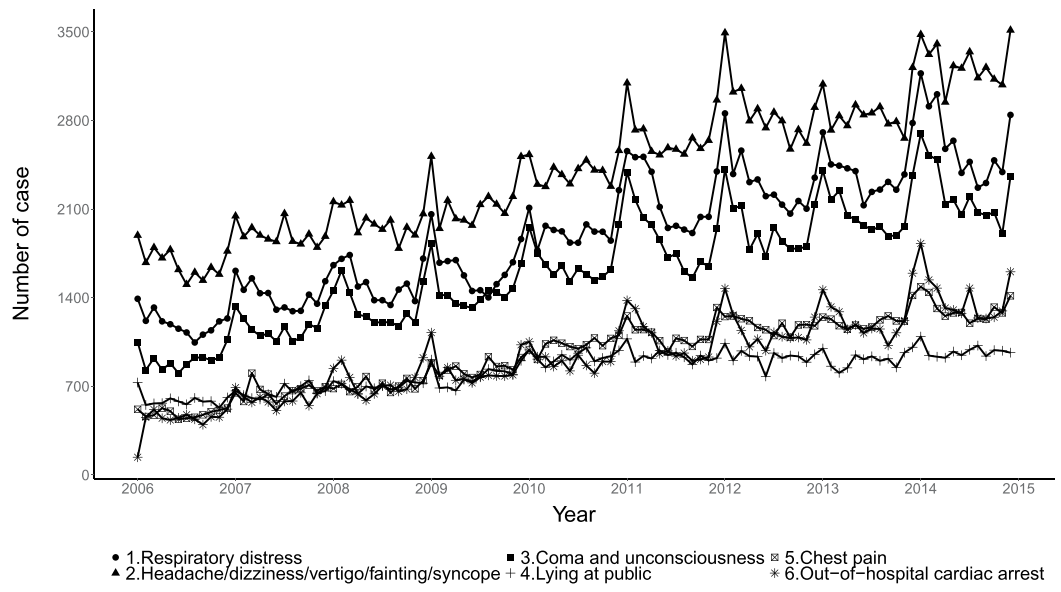

Figure 2. Monthly trends of cause-specific ambulance services from 2006 to 2014 in Taiwan.

$25^{\circ} \mathrm{C}$, which was the temperature related to the lowest ambulance call risk. The meta-analysis was fitted using a random-effects model with maximum likelihood ${ }^{26}$. The heterogeneity was evaluated using a multivariate extension of the $I^{2}$ value, where the values (ranging from $0-100 \%$ ) increased with increasing heterogeneity. All analyses in this study were carried out using the $m g c v, d l n m$, and mvmeta packages in R version 3.4.0.

\section{Results}

Climate characteristics and trends in the use of ambulance services from 2006 to 2014 . During the study period, the island-wide daily mean temperature was $23.4^{\circ} \mathrm{C}$ (range: $10.6-31.0^{\circ} \mathrm{C}$ ), with a mean relative humidity of $76.7 \%$ (range: $53.9-93.0 \%$ ), wind speed of $2.56 \mathrm{~m} / \mathrm{s}$ (range: $1.14-9.84 \mathrm{~m} / \mathrm{s}$ ), $\mathrm{NO}_{2}$ concentration of $14.6 \mu \mathrm{g} / \mathrm{m}^{3}$ (range: $3.32-35.8 \mu \mathrm{g} / \mathrm{m}^{3}$ ), $\mathrm{PM}_{10}$ concentration of $54.0 \mu \mathrm{g} / \mathrm{m}^{3}$ (range: $17.4-372 \mu \mathrm{g} / \mathrm{m}^{3}$ ) and $\mathrm{PM}_{2.5}$ concentration of $30.2 \mu \mathrm{g} / \mathrm{m}^{3}$ (range: $6.65-106 \mu \mathrm{g} / \mathrm{m}^{3}$ ) (Table 1 ). The mean daily numbers of cases requiring ambulance services were 79.6 for headaches/dizziness/vertigo/fainting/syncope, 53.4 for coma and unconsciousness, 63.0 for respiratory distress, 27.1 for lying down in public, 31.2 for chest pain, and 30.5 for OHCA.

Figure 2 shows the monthly cause-specific events that received ambulance services for the whole population of Taiwan; most types of incidents tended to increase from 2006 to 2014 except for OHCA. Annual peaks usually occurred in December and January during the cold season. The event type with the highest incidence was headaches/dizziness/vertigo/fainting/syncope, followed by respiratory distress, coma and unconsciousness, and chest pain. Supplementary Table 1 lists descriptive statistic for age and sex stratified case number from 2006 to 2014 in Taiwan except Taipei and New Taipei city.

Relative risk of events requiring ambulance services in relation to the ambient temperature and levels of $\mathbf{P M}_{10}$ and $\mathbf{P M}_{2.5}$. Figure 3 shows that the relative risks of the cause-specific events requiring 

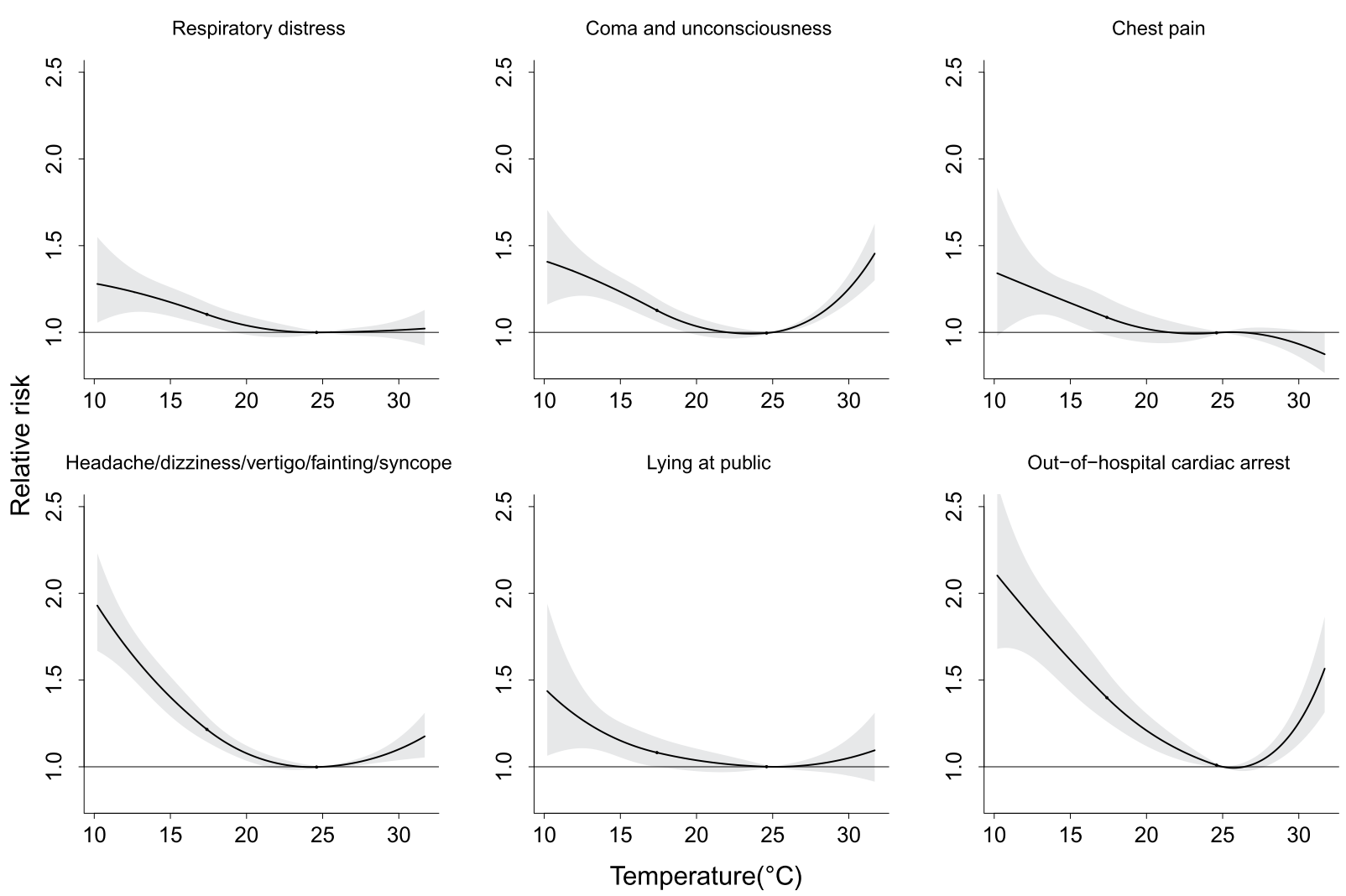

Figure 3. Relative risk of cause-specific disorders for ambulance ervices associated with daily average temperature relative to $25^{\circ} \mathrm{C}$ by meta-analysis.

\begin{tabular}{|l|l|l|l|l|}
\hline \multirow{2}{*}{} & \multicolumn{3}{|l|}{ Tavg. at $\mathbf{5}^{\text {th }}$ percentile $\left(\mathbf{1 5}^{\circ} \mathbf{C}\right)$} & \multicolumn{2}{l|}{ Tavg. at $\mathbf{9 9}^{\text {th }}$ percentile $\left(\mathbf{3 1}{ }^{\circ} \mathbf{C}\right)$} \\
\cline { 2 - 6 } & RR & $\mathbf{9 5 \%} \mathbf{C I}$ & $\mathbf{R R}$ & $\mathbf{9 5 \%}$ CI \\
\hline Respiratory distress & 1.15 & $(1.08-1.22)$ & 1.01 & $(0.93-1.09)$ \\
\hline Coma and unconsciousness & 1.23 & $(1.16-1.31)$ & 1.34 & $(1.23-1.46)$ \\
\hline Chest pain & 1.14 & $(1.05-1.25)$ & 0.91 & $(0.82-1.01)$ \\
\hline Headache/dizziness/vertigo/fainting/syncope & 1.41 & $(1.30-1.53)$ & 1.13 & $(1.04-1.22)$ \\
\hline Lying in public & 1.14 & $(1.04-1.23)$ & 1.09 & $(0.95-1.26)$ \\
\hline Out-of-hospital cardiac arrest & 1.61 & $(1.47-1.77)$ & 1.40 & $(1.25-1.57)$ \\
\hline
\end{tabular}

Table 2. Cause-specific relative risk ( $95 \%$ confidence interval) of ambulance services associated with the $5^{\text {th }}$ and $99^{\text {th }}$ percentile extreme temperatures. RR $(95 \% \mathrm{CI})$, relative risk (95\% confidence interval) estimated after controlling for PM2.5 and NO2 concentrations, wind speed, relative humidity, holiday effect, day of a week, mortality from pneumonia and influenza, and long-term time trend.

ambulance services were mainly v-shaped in relation to the daily mean temperature for all areas across Taiwan. Compared with the temperature of $25^{\circ} \mathrm{C}$, the risk was greater at low temperatures than at high temperatures, with a relative risk near 2.0 for the incidence of headaches/blackouts/fainting/syncope and OHCA when the temperature was $<10^{\circ} \mathrm{C}$. A completely inverse relationship appeared between the incidence of chest pain and the ambient temperatures. Fig. S6 illustrates the area-specific relationships between OHCA and temperature. An elevated RR for OHCA was observed in most areas when the temperature was low, mainly in Taoyuan, Hsincu, Miaoli, Taichung, Chunghua, Nantou, Yunlin, Tainan, Kaohsiung, Pingtung, and Yilan.

The cause-specific RRs for the use of ambulance services associated with extreme temperatures in the $5^{\text {th }}$ and $99^{\text {th }}$ percentile are presented in Table 2 . All 6 types of ambulance services were significantly elevated in the low-temperature environment $\left(<15^{\circ} \mathrm{C}\right)$, with the highest risk found for OHCA (RR $\left.=1.61 ; 95 \% \mathrm{CI}: 1.47-1.77\right)$. However, the risks were not significant at the extremely high temperatures of $>30^{\circ} \mathrm{C}$ for respiratory distress $(\mathrm{RR}=1.01 ; 95 \% \mathrm{CI}: 0.93-1.09)$ or chest pain $(\mathrm{RR}=0.91 ; 95 \% \mathrm{CI}: 0.82-1.01)$.

Figure 4 illustrates that the cause-specific RRs for the use of ambulance services increased with the daily mean $\mathrm{PM}_{10}$ concentration but were not significant. However, significant risks appeared for chest pain, headaches/ blackouts/fainting/syncope and OHCA when the $\mathrm{PM}_{2.5}$ concentration reached approximately $90 \mu \mathrm{g} / \mathrm{m}^{3}$ (Fig. 5). 

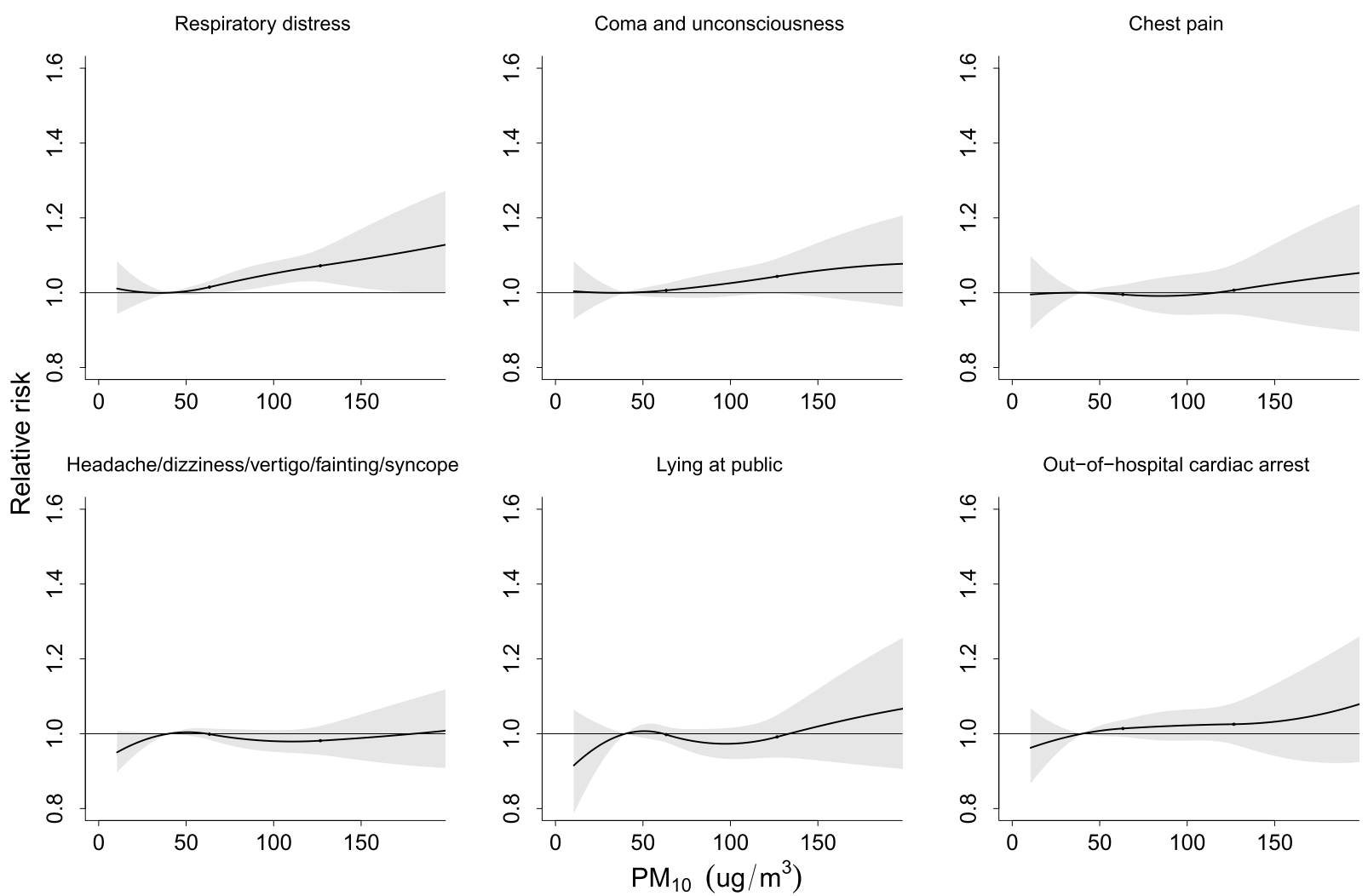

Figure 4. Relative risk of cause-specific disorders for ambulance services associated with daily $\mathrm{PM}_{10}$ concentrations relative to $40 \mu \mathrm{g} / \mathrm{m}^{3}$ level by meta-analysis after temperature adjusted.
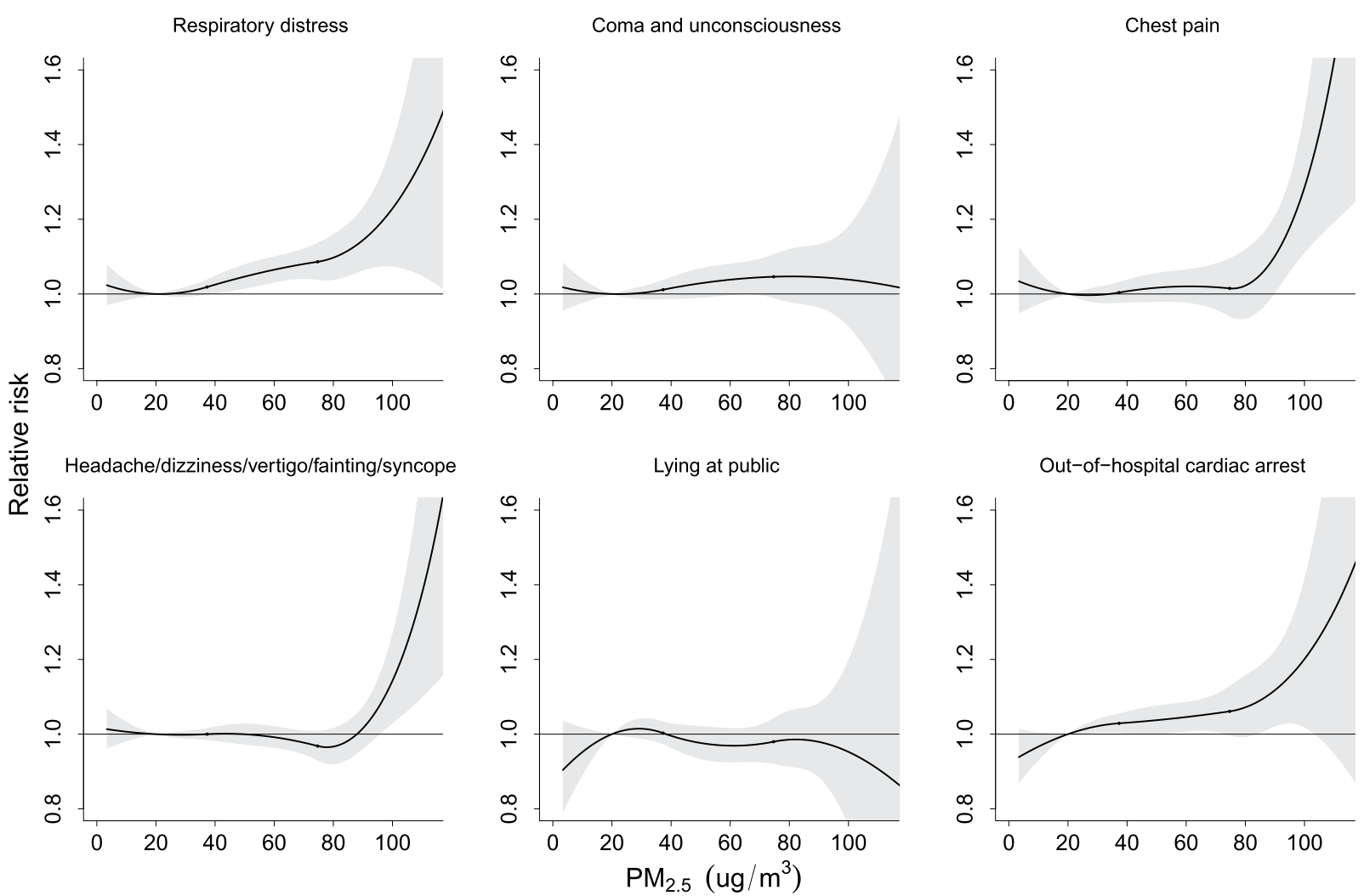

Figure 5. Relative risk of cause-specific disorders for ambulance services associated with daily $\mathrm{PM}_{2.5}$ concentrations relative to at $20 \mu \mathrm{g} / \mathrm{m}^{3}$ level by meta-analysis after temperature adjusted. 


\begin{tabular}{|c|c|c|c|c|}
\hline & \multicolumn{2}{|c|}{ Model without adjusting temperature } & \multicolumn{2}{|c|}{ Model adjusted temperature } \\
\hline & $\mathbf{R R}$ & $95 \% \mathrm{CI}$ & RR & $95 \% \mathrm{CI}$ \\
\hline \multicolumn{5}{|l|}{ Respiratory distress } \\
\hline $\mathrm{PM}_{10}, 99^{\text {th }}$ percentile & 1.05 & $(0.97-1.13)$ & 1.09 & $(1.01-1.18)$ \\
\hline $\mathrm{PM}_{2.5}, 99^{\text {th }}$ percentile & 1.10 & $(1.02-1.19)$ & 1.15 & $(1.07-1.24)$ \\
\hline \multicolumn{5}{|c|}{ Coma and unconsciousness } \\
\hline $\mathrm{PM}_{10}, 99^{\text {th }}$ percentile & 1.01 & $(0.94-1.09)$ & 1.06 & $(0.99-1.14)$ \\
\hline $\mathrm{PM}_{2.5}, 99^{\text {th }}$ percentile & 0.99 & $(0.92-1.07)$ & 1.04 & $(0.96-1.14)$ \\
\hline \multicolumn{5}{|l|}{ Chest pain } \\
\hline $\mathrm{PM}_{10}, 99^{\text {th }}$ percentile & 0.98 & $(0.88-1.10)$ & 1.03 & $(0.92-1.14)$ \\
\hline $\mathrm{PM}_{2.5}, 99^{\text {th }}$ percentile & 1.07 & $(0.98-1.18)$ & 1.11 & $(1.01-1.23)$ \\
\hline \multicolumn{5}{|c|}{ Headache/dizziness/vertigo/fainting/syncope } \\
\hline $\mathrm{PM}_{10}, 99^{\text {th }}$ percentile & 0.91 & $(0.86-0.97)$ & 0.99 & $(0.93-1.06)$ \\
\hline $\mathrm{PM}_{2.5}, 99^{\text {th }}$ percentile & 0.93 & $(0.88-0.99)$ & 1.02 & $(0.97-1.09)$ \\
\hline \multicolumn{5}{|l|}{ Lying in public } \\
\hline $\mathrm{PM}_{10}, 99^{\text {th }}$ percentile & 0.99 & $(0.90-1.09)$ & 1.02 & $(0.93-1.13)$ \\
\hline $\mathrm{PM}_{2.5}, 99^{\text {th }}$ percentile & 0.94 & $(0.84-1.04)$ & 0.98 & $(0.88-1.09)$ \\
\hline \multicolumn{5}{|c|}{ Out-of-hospital cardiac arrest } \\
\hline $\mathrm{PM}_{10}, 99^{\text {th }}$ percentile & 0.96 & $(0.87-1.06)$ & 1.03 & $(0.94-1.14)$ \\
\hline $\mathrm{PM}_{2.5}, 99^{\text {th }}$ percentile & 1.01 & $(0.92-1.11)$ & 1.12 & $(1.02-1.23)$ \\
\hline
\end{tabular}

Table 3. Cause-specific relative risk ( $95 \%$ confidence interval) of ambulance services associated with daily 99 th percentile $\mathrm{PM}_{10}\left(155 \mu \mathrm{g} / \mathrm{m}^{3}\right)$ and $\mathrm{PM}_{2.5}\left(91 \mu \mathrm{g} / \mathrm{m}^{3}\right)$ relative to Q1 levels $\left(40 \mu \mathrm{g} / \mathrm{m}^{3}\right.$ and $20 \mu \mathrm{g} / \mathrm{m}^{3}$, respectively). RR ( $95 \% \mathrm{CI})$, relative risk ( $95 \%$ confidence interval) estimated after controlling for temperature.

The cause-specific relative risks of events requiring ambulance services associated with the daily $99^{\text {th }}$ percentile of $\mathrm{PM}_{10}\left(155 \mu \mathrm{g} / \mathrm{m}^{3}\right)$ and $\mathrm{PM}_{2.5}\left(91 \mu \mathrm{g} / \mathrm{m}^{3}\right)$ relative to the Q1 levels $\left(40 \mu \mathrm{g} / \mathrm{m}^{3}\right.$ and $20 \mu \mathrm{g} / \mathrm{m}^{3}$, respectively) are shown in Table 3. After controlling for temperature, significant risks were observed for respiratory distress $(\mathrm{RR}=1.15$; 95\% CI: $1.07-1.24)$, chest pain $(\mathrm{RR}=1.11$; 95\% CI: $1.01-1.23)$ and OHCA (RR $=1.12$; 95\% CI: $1.02-$ 1.23) when people were exposed to levels of $\mathrm{PM}_{2.5}$ in the $99^{\text {th }}$ percentile.

\section{Discussion}

Ours study assessed the associations between daily usage of ambulance services and the ambient environmental conditions in Taiwan. This study defined extreme heat and cold as daily mean temperatures in the $99^{\text {th }}$ and $5^{\text {th }}$ percentiles of the temperature distribution. Low temperatures $\left(\leq 15^{\circ} \mathrm{C}\right)$ significantly elevated the risks of all ambulance events, with the highest relative risk for OHCA (RR $=1.61 ; 95 \%$ CI: $1.47-1.77)$. Ambulance care for comas and unconsciousness, OHCA and headaches/dizziness/vertigo/fainting/syncope were also associated with high temperatures $\left(\geq 31^{\circ} \mathrm{C}\right.$ ). High levels of $\mathrm{PM}_{2.5}$ (approximately $90 \mu \mathrm{g} / \mathrm{m}^{3}$ ) were found to be associated with minor increases in the risks of ambulance care for respiratory distress, chest pain, and OHCA (relative risk ranges from 1.11 to 1.15 ).

This study focused on ambulance calls based on the data from several reports. Respiratory diseases impose a large burden worldwide, and some of these diseases are categorized as the most common causes of severe illness and death worldwide ${ }^{27}$. Complaints of respiratory distress account for $13 \%$ of the total emergency medical services calls in the United States ${ }^{28}$. Unconsciousness also represented a relatively large proportion of the group requiring emergency medical services ${ }^{29}$. Chest pain was selected because it is involved in a higher frequency of emergency medical services, reaching as high as $14 \%$ of calls in the United States ${ }^{30}$. Headache symptoms are the most common disorder and have been reported by approximately $18 \%$ of women and $6 \%$ of men in the United States $^{31}$. El Sayed et al. recently reported that $60 \%$ of all emergency medical services were for OHCA in the United States $^{32}$. Our study showed that during the study period, headaches/dizziness/vertigo/fainting/syncope was the most prevalent event (27.9\%) requiring ambulance services, and lying down in the public was the least frequent event $(9.52 \%)$, whereas $10.7 \%$ of the services were for OHCA.

Limited reports have disclosed associations between the number of ambulance calls and the ambient environment $^{16,17,33-35}$. The temperature-health risk associations may vary across locations and health outcomes ${ }^{36}$. A study in Italy evaluated the cause and age stratification of ambulance dispatches in association with biometeorological discomfort and the apparent temperature in the region of Emilia-Romagna, which is located in northern Italy. Greater risks appeared when the daily mean apparent temperature exceeded $30^{\circ} \mathrm{C}$, and the risk increased with age $^{16}$. In Brisbane, the demand for heat-related ambulance calls increased immediately and lasted for 24 hours when the hourly temperature was higher than $27^{\circ} \mathrm{C}$, and the relative risk reached 1.8 when the temperature was $36^{\circ} \mathrm{C}^{34}$. A Huainan study in China found that extreme heat and heatwaves were significantly associated with increased emergency ambulance dispatches but that the risk may decrease with higher density and longer duration of the heatwaves ${ }^{33}$. In the present study, we also observed increased ambulance events when the daily mean temperature exceeded $27^{\circ} \mathrm{C}$. However, all events that required ambulance care were even more frequent when the temperature was lower than $18^{\circ} \mathrm{C}$. Studies have consistently reported that the subtropical climate in Taiwan is associated with greater health risks when temperatures are lower than when temperatures are higher ${ }^{37,38}$. The 
population in Taiwan may acclimatize to environments with higher temperatures and be sensitive to a climate with lower temperatures. Some studies have reported that the effects of cold temperatures are most significant in warm regions. People in warm regions are less adapted physically, socially, and behaviorally to low temperatures ${ }^{39}$. A study in Hong Kong found that the elderly were using ambulance services frequently due to their potential to suffer from cold temperatures below $12^{\circ} \mathrm{C}$, which is considered very cold in Hong Kong ${ }^{40}$.

This study agreed with the previous research that found $\mathrm{PM}_{2.5}$ to be significantly associated with respiratory tract diseases; the risk of respiratory tract diseases was greater in response to exposure to traffic-related air pollutants ${ }^{41}$. Chest pain was found to be significantly associated with $\mathrm{PM}_{2.5}$; in addition, a higher $\mathrm{PM}_{2.5}$ concentration may enhance the number of incidents of chest pain during warm days ${ }^{42}$. Kenneth et al. found that $\mathrm{PM}_{2.5} \mathrm{Could}$ trigger severe headaches by activating the sympathetic nervous system ${ }^{31}$.

This study showed that among the 6 categories of ambulance services, OHCA had the strongest RR in association with extreme temperatures and higher ambient levels of $\mathrm{PM}_{2.5}$. Studies in Japan have shown that the risk of OHCA was significantly elevated at low temperatures ${ }^{9,10,35}$. However, a study in Guangzhou, China, suggested that the OHCA risk increased on both cold and hot days and showed a J-shaped relationship with the temperature factors $^{35}$, similar to the pattern in Taiwan, where the risk was higher on cold days than on hot days. Low temperatures may increase blood viscosity, plasma viscosity, arterial pressure, and plasma cholesterol concentrations, thereby intensifying the stress on the cardiovascular system ${ }^{43}$.

The risk of OHCA increased with increasing ambient PM levels ${ }^{11,44-47}$. Ozone has also been associated with OHCA, while other pollutants are less likely to be associated with $\mathrm{OHCA}^{48}$. A Korean study reported that the OHCA risk increased by $1.30 \%$ after 1 to 2 days of exposure to $\mathrm{PM}_{2.5}$, with an elevation of $10 \mu \mathrm{g} / \mathrm{m}^{344}$. The impact of $\mathrm{PM}_{2.5}$ on OHCA has been shown from an immediate effect (a few hours or same-day exposure prior to OHCA) to a lag of 2 days $^{49}$. The pathogenicity of PM is determined by its size. PM with aerodynamic diameters smaller than $10 \mu \mathrm{m}$ has a greater impact on human health than PM with a larger diameter. The major components of $\mathrm{PM}_{2.5}$ are inorganic sulfate, organic carbon, trace elements and ammonium ${ }^{50}$, while $\mathrm{PM}_{10}$ consists of crustal dust, secondary sulfate and nitrate, metal emission source and vehicle exhaust ${ }^{51}$. $\mathrm{PM}_{2.5}$ particles are characterized by a small diameter $(<2.5 \mu \mathrm{m})$ and are able to carry various toxic substances; they are not filtered by the nose and reach to the end of the respiratory tract with the airflow, accumulating by diffusion and damaging other parts of the body through air exchange with the lungs ${ }^{52}$. For the present study, the regional associations between the cause-specific ambulance services and the ambient $\mathrm{PM}_{10} / \mathrm{PM}_{2.5}$ concentrations are shown in Figs. S7-S18. To date, no conclusive evidence has suggested that the OHCA risk is linked to exposure to airborne pollutants. In addition to OHCA, the present study also observed some significant risks associated with higher PM concentrations, which mainly occurred in central and southern Taiwan.

Taiwan is a relatively small island, but our study demonstrated that the linkage between OHCA and temperature varied among geographic areas. Elevated OHCA risk was found with low temperatures in most study areas, except in Keelung, Chiayi, Hualien and Taitung. On the other hand, the elevated OHCA risk was also found in populations exposed to extremely high temperatures in Keelung, Miaoli, Chunghua, Chiayi, Tainan, Kaohsiung, Hualien and Taitung (Supplementary Fig. S6). These findings agreed with our previous reports, which indicated that the temperature-health association in Taiwan exhibited spatial heterogeneity ${ }^{4,37,38}$. The acclimatization and adaptive capacity of people to extreme temperatures likely varies among areas.

In addition to OHCA, other types of ambulance events, including respiratory distress, coma and unconsciousness, chest pain, and headaches/dizziness/vertigo/fainting/syncope, were also associated with the ambient temperatures in Taiwan, especially for the major cities, namely, Taoyuan, Tainan and Kaohsiung. Overall, there was a more significant relationship associated with lower temperatures than with higher temperatures. Our data agreed with those from a previous study, which reported that people living in warm climates were generally more vulnerable to cold ${ }^{23}$. The connection of these general symptoms with the development of specific diseases and the mechanisms associated with the ambient temperatures require future research.

The association between temperature and $\mathrm{PM}_{10}$ and $\mathrm{PM}_{2.5}$ and mortality and morbidity has been reported in several studies ${ }^{53,54}$. A study in Brisbane and Italy found that the health effect of $\mathrm{PM}_{10}$ increased on warmer days ${ }^{53,54}$, while a study in Hong Kong discovered a greater effect of $\mathrm{PM}_{2.5}$ on respiratory mortality in low temperature ranges than in high temperature ranges ${ }^{55}$. The present study showed that the relative risks of respiratory distress, chest pain, and OHCA among ambulance services associated with daily $\mathrm{PM}_{10}$ and $\mathrm{PM}_{2.5}$ in the $99^{\text {th }}$ percentile increased after controlling for temperature (Table 3). In addition, the association of daily $\mathrm{PM}_{10}$ and $\mathrm{PM}_{2.5}$ in the $75^{\text {th }}$ percentile with the use of ambulance services has been analyzed. The risk was only significant for respiratory distress and OHCA. Although the mechanism of the interaction between air pollution and temperature remains unclear, some possible explanations have been proposed. The effect of $\mathrm{PM}_{2.5}$ with high temperatures may be linked to the direct or indirect responses of organisms to heat stress. Low temperatures may cause physiologic stress, thus reducing the physiologic response to air pollution; as a result, people are more susceptible to air pollution ${ }^{55,56}$. In cold seasons, particularly with extremely low temperatures in the $5^{\text {th }}$ percentile, temperature inversion occurs and consequently exacerbates the accumulation of $\mathrm{PM}_{10}$ and $\mathrm{PM}_{2.5}$. We should take note of the confounding characteristics of PM exposure.

The associations between the ambient temperature and health indicators, such as mortality, emergency room visits and outpatient visits, are varied due to population variations in health status, socioeconomics, and access to medical services ${ }^{36}$. The amount of time from exposure to the ambient environment to the development of health events also varies with health indicators. The information on this topic remains unclear due to limited population-based studies worldwide. The progression of disease, from early symptoms, outpatient visits, emergency room visits and ambulance services to death, represents the various patterns for disease severity associated with risk factors. Identifying the risks in an earlier stage of disease may provide critical information for population health interventions and policy planning for future medical services. 
The present study has several strengths. The wide data coverage from the Taiwan ambulance services program and all ambient air quality data ensures the representativeness of exposure for the entire population. The confounding factors, such as the holiday effect, day of the week, long-term trends, and risks associated with infectious pneumonia and influenza, were considered in the data analysis models.

Despite the contributions of this study, there were some limitations. First, our work was an ecological study. The risk was not estimated with individual-based data. In addition, information on some factors that may modify the risk associated with ambulance events, such as smoking, drinking, exercise and socioeconomic status, was not available for evaluation ${ }^{57-59}$. The hourly measurements of the ambient environment associated with cause-specific ambulance services require further investigation to control for these factors. The patient diagnoses in the medical records of the ambulance services were based on observers conducting the services. No ICD codes were provided.

The rapid increase in the demand for ambulance services in Taiwan with extremely high and low temperatures and air pollution events is a critical issue that should be the focus of the government. Our current study reports that extreme temperatures play a more important role than air pollution in increasing the number of ambulance events. Therefore, our research suggests that the public health sector should take several actions, such as examining ambulance calls, especially during extremely cold temperatures and summer activities; providing medical preparation in critical conditions; and providing educational campaigns for the community to increase their awareness.

\section{Conclusions}

This population-based study evaluated the association of events requiring ambulance services, including respiratory distress, coma and unconsciousness, chest pain, headaches/dizziness/vertigo/fainting/syncope, lying down in public, and OHCA, with ambient environmental conditions in Taiwan. The population of the island had a higher risk of OHCA in response to exposure to cold temperatures than in response to hot temperatures, although only $10.7 \%$ of ambulance services were for OHCA. In addition, ambulance care for coma and unconsciousness and headaches/dizziness/vertigo/fainting/syncope were also elevated in extreme heat exposure. The high level of PM may slightly increase the frequency of emergency medical care for respiratory distress, chest pain, and OHCA after controlling for temperature. Among the studied ambulance events, the incidence of OHCA was the most vulnerable to extreme temperatures and higher levels of $\mathrm{PM}_{2.5}$. This study provides critical information to health authorities for the development of future ambulance service plans.

Received: 2 August 2019; Accepted: 20 January 2020;

Published online: 18 February 2020

\section{References}

1. Frumkin, H., Hess, J., Luber, G., Malilay, J. \& McGeehin, M. Climate Change: The Public Health Response. Am. J. Public. Health 98, 435-445 (2008)

2. Zhang, Y. et al. Effect of ambient temperature on emergency department visits in Shanghai, China: a time series study. Environmental Health 13, (2014).

3. Guo, Y. et al. Global variation in the effects of ambient temperature on mortality: a systematic evaluation. Epidemiol. 25, 781-789 (2014).

4. Wang, Y. C. et al. Associating emergency room visits with first and prolonged extreme temperature event in Taiwan: A populationbased cohort study. Sci. Total. Env. 416, 97-104 (2012).

5. Curriero, F. C. Temperature and Mortality in 11 Cities of the Eastern United States. Am. J. Epidemiol. 155, 80-87 (2002).

6. McMichael, A. J. et al. International study of temperature, heat and urban mortality: the 'ISOTHURM' project. Int. J. Epidemiol. 37, 1121-1131 (2008).

7. Anderson, B. G. \& Bell, M. L. Weather-Related Mortality. Epidemiol. 20, 205-213 (2009).

8. Baccini, M. et al. Heat Effects on Mortality in 15 European Cities. Epidemiol. 19, 711-719 (2008).

9. Nishiyama, C. et al. Association of out-of-hospital cardiac arrest with prior activity and ambient temperature. Resuscitation 82, 1008-1012 (2011)

10. Tanigawa-Sugihara, K. et al. Association between atmospheric conditions and occurrence of out-of-hospital cardiac arrest- 10-year population-based survey in Osaka. Circ. J. 77, 2073-2078 (2013).

11. Dai, J. P. et al. Ambient air pollution, temperature and out-of-hospital coronary deaths in Shanghai, China. Env. Pollut. 203, 116-121 (2015).

12. Wang, Y. C., Chen, Y. C., Ko, C. Y., Guo, Y. L. \& Sung, F. C. Pre-existing comorbidity modify emergency room visit for out-ofhospital cardiac arrest in association with ambient environments. PLoS One 13, e0204593 (2018).

13. Chen, K. et al. Two-way effect modifications of air pollution and air temperature on total natural and cardiovascular mortality in eight European urban areas. Env. Int. 116, 186-196 (2018).

14. Andersen, Z. J. et al. Long-term exposure to air pollution and asthma hospitalisations in older adults: a cohort study. Thorax 67, 6-11 (2012).

15. Cheng, M. F. et al. Air pollution and hospital admissions for pneumonia: are there potentially sensitive groups? Inhal. Toxicol. 21, 1092-1098 (2009)

16. Alessandrini, E. et al. Emergency ambulance dispatches and apparent temperature: a time series analysis in Emilia-Romagna, Italy. Env. Res. 111, 1192-1200 (2011)

17. Onozuka, D. \& Hagihara, A. Spatial and temporal variation in emergency transport during periods of extreme heat in Japan: A nationwide study. Sci. Total. Env. 544, 220-229 (2016).

18. Wong, H. T., Lin, T. K. \& Lin, J. J. Identifying rural-urban differences in the predictors of emergency ambulance service demand and misuse. J. Formos. Med. Assoc. 118, 324-331 (2019).

19. Lori Uscher-Pines, P., Jesse, P., Arthur, K. \& Emily Gillen, A. A. M. Deciding to Visit the Emergency Department for Non-Urgent Conditions: A Systematic Review of the Literature. Am. J. Manag. Care 19(1), 47-59 (2013).

20. Enayati, S., Mayorga, M. E., Rajagopalan, H. K. \& Saydam, C. Real-time ambulance redeployment approach to improve service coverage with fair and restricted workload for EMS providers. Omega 79, 67-80 (2018).

21. Meghoo, C. A., Gaievskyi, S., Linchevskyy, O., Oommen, B. \& Stetsenko, K. Prehospital response to respiratory distress by the public ambulance system in a Ukrainian city. World J. Emerg. Med. 10, 42-45 (2019).

22. Mahmood, M., Thornes, J., Pope, F., Fisher, P. \& Vardoulakis, S. Impact of Air Temperature on London Ambulance Call-Out Incidents and Response Times. Climate 5 (2017). 
23. Yang, L.-T., Chang, Y.-M., Hsieh, T.-H., Hou, W.-H. \& Li, A. C.-Y. Associations of Ambient Temperature with Mortality Rates of Cardiovascular and Respiratory Diseases in Taiwan: A Subtropical Country. Acta Cardiol Sin 2018, 34(166), 174 (2018).

24. Gasparrini, A., Armstrong, B. \& Kenward, M. G. Distributed lag non-linear models. Stat. Med. 29, 2224-2234 (2010).

25. Phung, D. et al. Ambient temperature and risk of cardiovascular hospitalization: An updated systematic review and meta-analysis. Sci. Total. Env. 550, 1084-1102 (2016).

26. Viechtbauer, W. Conducting Meta-Analyses in R with the metafor Package. Journal of Statistical Software 36, (2010).

27. Organization, W. H. The Global Impact of Respiratory Disease. (2017).

28. Aguilar, S. A. et al. Assessment of the addition of prehospital continuous positive airway pressure (CPAP) to an urban emergency medical services (EMS) system in persons with severe respiratory distress. J. Emerg. Med. 45, 210-219 (2013).

29. Park, H. A., Ahn, K. O., Shin, S. D., Cha, W. C. \& Ro, Y. S. The Effect of Emergency Medical Service Use and Inter-hospital Transfer on Prehospital Delay among Ischemic Stroke Patients: A Multicenter Observational Study. J. Korean Med. Sci. 31, 139-146 (2016).

30. Nehme, Z. et al. Effect of a mass media campaign on ambulance use for chest pain. Med. J. Aust. 206, 30-35 (2017).

31. Mukamal, K. J. et al. Weather and air pollution as triggers of severe headaches. Neurology 72 (2009).

32. El Sayed, M. et al. Measuring the impact of emergency medical services (EMS) on out-of-hospital cardiac arrest survival in a developing country: A key metric for EMS systems' performance. Med. 96, e7570 (2017).

33. Cheng, J. et al. The burden of extreme heat and heatwave on emergency ambulance dispatches: A time-series study in Huainan, China. Sci. Total. Env. 571, 27-33 (2016).

34. Guo, Y. Hourly associations between heat and ambulance calls. Env. Pollut. 220, 1424-1428 (2017).

35. Niu, Y. et al. The association between ambient temperature and out-of-hospital cardiac arrest in Guangzhou, China. Sci. Total. Env. 572, 114-118 (2016).

36. Lin, Y. K., Maharani, A. T., Chang, F. T. \& Wang, Y. C. Mortality and morbidity associated with ambient temperatures in Taiwan. Sci. Total. Env. 651, 210-217 (2019).

37. Lin, Y. K., Chang, C. K., Wang, Y. C. \& Ho, T. J. Acute and prolonged adverse effects of temperature on mortality from cardiovascular diseases. PLoS One 8, e82678 (2013).

38. Lin, Y.-K., Ho, T.-J. \& Wang, Y.-C. Mortality risk associated with temperature and prolonged temperature extremes in elderly populations in Taiwan. Environ. Res. 111, 1156-1163 (2011).

39. Yi, W. \& Chan, A. P. Effects of temperature on mortality in Hong Kong: a time series analysis. Int. J. Biometeorol. 59, 927-936 (2015).

40. Lai, P. C. \& Wong, H. T. Weather and age-gender effects on the projection of future emergency ambulance demand in Hong Kong. Asia Pac. J. Public. Health 27, NP2542-2554 (2015).

41. Liu, Q. et al. Effect of exposure to ambient PM2.5 pollution on the risk of respiratory tract diseases: a meta-analysis of cohort studies. J. Biomed. Res. 31, 130-142 (2017).

42. Chen, C. C. \& Yang, C. Y. Association between fine particulate air pollution and hospital admissions for chest pain in a subtropical city: Taipei, Taiwan. J. Toxicol. Env. Health A 80, 1269-1275 (2017).

43. Keatinge, W. R. et al. Increases in platelet and red cell counts, blood viscosity, and arterial pressure during mild surface cooling: factors in mortality from coronary and cerebral thrombosis in winter. Br. Med. J. 289, 1405-1408 (1984).

44. Kang, S. H. et al. Ambient air pollution and out-of-hospital cardiac arrest. Int. J. Cardiol. 203, 1086-1092 (2016).

45. Pradeau, C. et al. Air pollution and activation of mobile medical team for out-of-hospital cardiac arrest. Am. J. Emerg. Med. 33, 367-372 (2015).

46. Rosenthal, F. S. et al. Association of ozone and particulate air pollution with out-of-hospital cardiac arrest in Helsinki, Finland: evidence for two different etiologies. J. Expo. Sci. Env. Epidemiol. 23, 281-288 (2013).

47. Straney, L. et al. Evaluating the impact of air pollution on the incidence of out-of-hospital cardiac arrest in the Perth Metropolitan Region: 2000-2010. J. Epidemiol. Community Health 68, 6-12 (2014).

48. Teng, T. H. et al. A systematic review of air pollution and incidence of out-of-hospital cardiac arrest. J. Epidemiol. Community Health 68, 37-43 (2014).

49. Ensor, K. B., Raun, L. H. \& Persse, D. A case-crossover analysis of out-of-hospital cardiac arrest and air pollution. Circulation 127, 1192-1199 (2013).

50. Hsu, C. Y. et al. Ambient PM2.5 in the residential area near industrial complexes: Spatiotemporal variation, source apportionment, and health impact. Sci. Total. Env. 590-591, 204-214 (2017).

51. Liang, C.-S., Yu, T.-Y., Chang, Y.-Y., Syu, J.-Y. \& Lin, W.-Y. Source Apportionment of PM2.5 Particle Composition and Submicrometer Size Distribution during an Asian Dust Storm and Non-Dust Storm in Taipei. Aerosol Air Qual. Res. 13, 545-554 (2013).

52. Xing, Y. F., Xu, Y. H., Shi, M. H. \& Lian, Y. X. The impact of PM2.5 on the human respiratory system. J. Thorac. Dis. 8, E69-74 (2016).

53. Ren, C. \& Tong, S. Temperature modifies the health effects of particulate matter in Brisbane, Australia. Int. J. Biometeorol. 51, 87-96 (2006).

54. Stafoggia, M., Schwartz, J., Forastiere, F., Perucci, C. A. \& Group, S. Does temperature modify the association between air pollution and mortality? A multicity case-crossover analysis in Italy. Am. J. Epidemiol. 167, 1476-1485 (2008).

55. Sun, S. et al. Temperature as a modifier of the effects of fine particulate matter on acute mortality in Hong Kong. Env. Pollut. 205, 357-364 (2015).

56. Rodrigues, P. C. O., Pinheiro, S. L., Junger, W., Ignotti, E. \& Hacon, S. S. Climatic variability and morbidity and mortality associated with particulate matter. Rev. Saude Publica 51, 91 (2017).

57. Sacks, J. D. et al. Particulate matter-induced health effects: who is susceptible? Env. Health Perspect. 119, 446-454 (2011).

58. Bell, M. L., Zanobetti, A. \& Dominici, F. Evidence on vulnerability and susceptibility to health risks associated with short-term exposure to particulate matter: a systematic review and meta-analysis. Am. J. Epidemiol. 178, 865-876 (2013).

59. Zipes, D. P. \& Wellens, H. J. Sudden cardiac death. Circulation 98, 2334-2351 (1998).

\section{Acknowledgements}

We would like to thank the Ministry of Health and Welfare, Environmental Protection Agency and Central Weather Bureau, Executive Yuan for providing research data. Interpretations and conclusions herein do not necessarily represent the views of these agencies. This study was supported in part by grants from the Taiwan Ministry of Science and Technology (MOST 106-2621-M-033-001-and MOST 106-2221-E-033-006-MY2), National Health Research Institutes (NHRI-107A1-EMCO-3617191, NHRI-106A1-PDCO-3617191 and MOHW105-TDU-M-212-113003), and Taiwan CWB (MP10501-0125), the Ministry of Health and Welfare, Taiwan (MOHW108-TDU-B-212-133004), China Medical University Hospital, Academia Sinica Stroke Biosignature Project (BM10701010021), MOST Clinical Trial Consortium for Stroke (MOST 106-2321-B-039005), Tseng-Lien Lin Foundation, Taichung, Taiwan, and Katsuzo and Kiyo Aoshima Memorial Funds, Japan. The employment status of authors are shown in the title page. 


\section{Author contributions}

All authors were involved in designing the study, Y.C.W. and Y.K.L. drafted the manuscript, Y.J.C., Y.C.W. and S.C.H. analyzed the data, and Y.C.W., Y.Z. and F.C.S. finalized the manuscript. All have read and approved the final version of the manuscript.

\section{Competing interests}

The authors declare no competing interests.

\section{Additional information}

Supplementary information is available for this paper at https://doi.org/10.1038/s41598-020-59294-8.

Correspondence and requests for materials should be addressed to F.-C.S.

Reprints and permissions information is available at www.nature.com/reprints.

Publisher's note Springer Nature remains neutral with regard to jurisdictional claims in published maps and institutional affiliations.

(c) (i) Open Access This article is licensed under a Creative Commons Attribution 4.0 International License, which permits use, sharing, adaptation, distribution and reproduction in any medium or format, as long as you give appropriate credit to the original author(s) and the source, provide a link to the Creative Commons license, and indicate if changes were made. The images or other third party material in this article are included in the article's Creative Commons license, unless indicated otherwise in a credit line to the material. If material is not included in the article's Creative Commons license and your intended use is not permitted by statutory regulation or exceeds the permitted use, you will need to obtain permission directly from the copyright holder. To view a copy of this license, visit http://creativecommons.org/licenses/by/4.0/.

(c) The Author(s) 2020 